\title{
Assessment of regional aerosol radiative effects under the SWAAMI campaign - Part 2: Clear-sky direct shortwave radiative forcing using multi-year assimilated data over the Indian subcontinent
}

\author{
Harshavardhana Sunil Pathak ${ }^{1}$, Sreedharan Krishnakumari Satheesh ${ }^{1,2}$, Krishnaswamy Krishna Moorthy ${ }^{1}$, and \\ Ravi Shankar Nanjundiah ${ }^{1,2,3}$ \\ ${ }^{1}$ Centre for Atmospheric and Oceanic Sciences, Indian Institute of Science, Bengaluru, India \\ ${ }^{2}$ DST-Centre of Excellence in Climate Change, Divecha Centre for Climate Change, \\ Indian Institute of Science, Bengaluru, India \\ ${ }^{3}$ Indian Institute of Tropical Meteorology, Pune, India
}

Correspondence: Harshavardhana Sunil Pathak (rhsp19@gmail.com)

Received: 10 May 2020 - Discussion started: 25 May 2020

Revised: 30 August 2020 - Accepted: 11 September 2020 - Published: 23 November 2020

\begin{abstract}
Clear-sky, direct shortwave aerosol radiative forcing (ARF) has been estimated over the Indian region, for the first time employing multi-year (2009-2013) gridded, assimilated aerosol products, as an important part of the South West Asian Aerosol Monsoon Interactions (SWAAMI) which is a joint Indo-UK research field campaign focused at understanding the variabilities in atmospheric aerosols and their interactions with the Indian summer monsoon. The aerosol datasets have been constructed following statistical assimilation of concurrent data from a dense network of ground-based observatories and multi-satellite products, as described in Part 1 of this two-part paper. The ARF, thus estimated, is assessed for its superiority or otherwise over other ARF estimates based on satellite-retrieved aerosol products, over the Indian region, by comparing the radiative fluxes (upward) at the top of the atmosphere (TOA) estimated using assimilated and satellite products with spatiotemporally matched radiative flux values provided by CERES (Clouds and Earth's Radiant Energy System) single-scan footprint (SSF) product. This clearly demonstrated improved accuracy of the forcing estimates using the assimilated vis-àvis satellite-based aerosol datasets at regional, subregional and seasonal scales. The regional distribution of diurnally averaged ARF estimates has revealed (a) significant differences from similar estimates made using currently available satellite data, not only in terms of magnitude but also the sign of TOA forcing; (b) the largest magnitudes of
\end{abstract}

surface cooling and atmospheric warming over the IndoGangetic Plain (IGP) and arid regions from north-western India; and (c) negative TOA forcing over most parts of the Indian region, except for three subregions - the IGP, northwestern India and eastern parts of peninsular India where the TOA forcing changes to positive during pre-monsoon season. Aerosol-induced atmospheric warming rates, estimated using the assimilated data, demonstrate substantial spatial heterogeneities $\left(\sim 0.2\right.$ to $\left.2.0 \mathrm{~K} \mathrm{~d}^{-1}\right)$ over the study domain with the IGP demonstrating relatively stronger atmospheric heating rates $\left(\sim 0.6\right.$ to $\left.2.0 \mathrm{~K} \mathrm{~d}^{-1}\right)$. There exists a strong seasonality as well, with atmospheric warming being highest during pre-monsoon and lowest during winter seasons. It is to be noted that the present ARF estimates demonstrate substantially smaller uncertainties than their satellite counterparts, which is a natural consequence of reduced uncertainties in assimilated vis-à-vis satellite aerosol properties. The results demonstrate the potential application of the assimilated datasets and ARF estimates for improving accuracies of climate impact assessments at regional and subregional scales. 


\section{Introduction}

The uncertainties in aerosol radiative forcing (ARF) pose primary challenges in the assessment of climatic implications of atmospheric aerosols at global, regional and even subregional scales (Schwartz, 2004; Boucher et al., 2013). In order to improve the estimates of aerosol climate sensitivity, an at least 3-fold reduction in the uncertainties in aerosol radiative forcing is necessary (Schwartz, 2004). Despite efforts towards this, significant uncertainties still persist in the estimates of even direct aerosol radiative forcing (DARF) (Penner et al., 1994; Boucher and Anderson, 1995; Ramanathan and Carmichael, 2008), aside from the indirect forcing. This calls for improvement in the accuracy of primary aerosol inputs to DARF estimation at subregional and regional scales.

There have been several estimates of global ARF by employing general circulation models (GCMs) or chemistry transport models (CTMs) making use of aerosol emission inventories (Jacobson, 2001; Takemura et al., 2002; Myhre et al., 2007, 2009; Kim et al., 2008). These studies have highlighted the regional and temporal heterogeneity in aerosol forcing, but the actual forcing values reported have significant uncertainties emanating mainly from those in the input inventories, meteorology and assumptions made in aerosolchemistry processing. Schulz et al. (2006) have shown that the model-based (GCM or CTM) estimates of radiative forcing differ significantly amongst themselves, even in terms of sign of radiative forcing, despite using identical emission inventories. Recognizing this issue, Chung et al. $(2005,2010)$ have produced global and regional maps of aerosol forcing employing observationally constrained aerosol datasets, which were constructed by integrating satellite and groundbased observations of aerosol optical depth (AOD) with those derived from the global Goddard Chemistry Aerosol Radiation and Transport (GOCART) model. They provided somewhat more realistic estimates of aerosol forcing compared to those incorporating model-derived aerosol parameters because of the improvements in the input datasets arising from their assimilation efforts. Nevertheless, due to limited number of regional ground stations involved in the assimilation process by Chung et al. (2005) (for example, only two stations over the Indian region), the assimilated AODs over large parts of the globe remained largely represented by satellite-retrieved and model-derived AODs, which suffer from significant uncertainties and biases emanating from a variety of sources (cloud contamination, spatial heterogeneities in surface albedo, sparse temporal sampling, various assumption made during the retrieval procedure and sensor degradation, etc.) (Zhang and Reid, 2006; Jethva et al., 2014). As a result, large uncertainties still prevailed at regional and subregional scales.

Location-specific estimates are more accurate as these employ highly accurate ground-based measurements of aerosol properties (spectral AOD, aerosol absorption, altitude profiles, etc.) and generate aerosol models constrained with mea- surements and use them in a radiative transfer scheme (Babu and Moorthy, 2002; Suresh Babu et al., 2007; Satheesh et al., 2006; Pathak et al., 2010; Sinha et al., 2013). Due to smaller uncertainties in the direct measurements, these aerosol forcing estimates tend to have lesser uncertainties vis-à-vis forcing estimates from satellite-retrieved and model-derived aerosol parameters. However, due to limited spatial representativeness of each ground station and the limited density of ground networks, these ARF estimates are highly location specific. They lack the much-needed regional representativeness for climate assessment, unless they involve a large number of ground locations, from a highly dense network, which has associated practical difficulties. Recognizing these scenarios, especially over the Indian region which has large spatiotemporal variations in aerosol properties, a careful assimilation of moderately dense network data with satellite data to generate a gridded dataset which is more or less continuous in space and time has been envisioned as one of the key objectives by the South West Asian Aerosol Monsoon Interactions (SWAAMI; https://gtr.ukri. org/projects?ref=NE/L013886/1, last access: 9 May 2020), a coordinated field campaign jointly undertaken by the scientists from India and the United Kingdom.

In Part 1 of this two-part paper, we have presented the gridded, assimilated datasets of AOD and single scattering albedo (SSA) over India, which provide spatiotemporally continuous data, generated for the first time by harmonizing long-term (2009-2013) measurements from a dense network of ground-based aerosol observatories and multisatellite datasets following statistical assimilation techniques (Pathak et al., 2019). The resulting improvement in accuracies of the gridded products (over the parent data) in reproducing the spatiotemporal characteristics of aerosol properties at subregional scales over the Indian domain was also demonstrated. In Part 2 of the paper, we have estimated the direct shortwave aerosol ARF over the Indian region using the above gridded data and examined its features. A comparison of these estimates is done with similar estimates made using the parent satellite data to demonstrate the effectiveness of the assimilated data in better quantifying ARF over the Indian region with its characteristic spatiotemporal features. Further, we have compared the top-of-the-atmosphere (TOA) flux estimated using the assimilated data with the instantaneous flux values measured by the Clouds and Earth's Radiant Energy System (CERES) instrument, and the seasonal contrast in ARF is then presented for various geographically homogeneous subregions. The primary findings of the present work are then summarized.

\section{Database}

Accuracy of estimation of direct aerosol radiative effect depends strongly on the accuracies of three key optical properties of aerosols, namely AOD, SSA and single-scatter phase 
function, and the availability of these continuously in space and time over the domain of interest. Accordingly, in this work, we have used the gridded data over the Indian domain for AOD and SSA at $1^{\circ} \times 1^{\circ}$ resolution. These datasets are generated by assimilating long-term data from groundbased network observatories and space-borne sensors following statistical assimilation techniques (3D-Var and weighted interpolation methods) as described in Pathak et al. (2019) (Part 1) and are available at http://dccc.iisc.ac.in/aerosoldata/ (last access: 9 May 2020). These assimilated AOD and SSA are henceforth, respectively, denoted as AS AOD and AS SSA. However, such a comprehensive dataset for aerosol phase function is not available over the study domain, and as such we relied on the Optical Properties of Aerosols and Clouds (OPAC) model (Hess et al., 1998), which provides optical properties for variety aerosol species and their mixtures (under externally mixed assumption). As our study domain is mainly comprised of land areas, an average value of aerosol phase function (at $550 \mathrm{~nm}$ ) corresponding to all continental aerosol mixtures in OPAC is considered, and its Legendre polynomial coefficients (eight streams) are employed for determining the Legendre moments of the phase function.

In addition to assimilated aerosol products, we have also employed satellite-retrieved AOD and SSA (denoted as SR AOD and SR SSA, respectively) for ARF estimation. The satellite-retrieved AODs employed here are constructed by combining by monthly averaged AOD products $\left(1^{\circ} \times 1^{\circ}\right.$ resolution) from (L3, Collection 6; https://modis.gsfc.nasa.gov/ data/, last access: 9 May 2020) MODerate Imaging Spectroradiometer (MODIS) aboard the Aqua and Terra satellites as well as from Multiangle Imaging SpectroRadiometer (MISR) aboard the Terra satellite (L3; https://misr.jpl.nasa. gov/, last access: 9 May 2020) (Diner et al., 1998), as detailed in Part 1 of the two-part paper (Pathak et al., 2019). The satellite-retrieved SSAs are provided by monthly mean SSA (at $500 \mathrm{~nm}$ ) datasets constructed from upwelling radiance measurements (in the range of 270-500 $\mathrm{nm}$ ) performed by the Ozone Monitoring Instrument (OMI) aboard the Aura satellite (Torres et al., 2007; Levelt et al., 2006).

The spatial distributions of the gridded aerosol properties (assimilated as well as satellite retrieved; AODs and SSA) are shown in Fig. 1 for two typical months; January - typical winter, when the majority of aerosols are trapped near the surface due to the shallow atmospheric boundary layer; and May - typical summer/pre-monsoon when the strong thermal convection ensures a thorough vertical mixing within the deep atmospheric boundary layer (ABL) (Kompalli et al., 2014). These two months also signify periods when the local emissions dominate in the aerosol loading (winter) and when advected aerosols (dust and sea salt) also contribute significantly to the aerosol loading (summer/pre-monsoon) (Moorthy et al., 2005; Krishna Moorthy et al., 2007; Jethva et al., 2005; Niranjan et al., 2007). Subregional differences in the spatial distribution of these parameters between the assimilated and satellite-retrieved products are noticeable in Fig. 1,
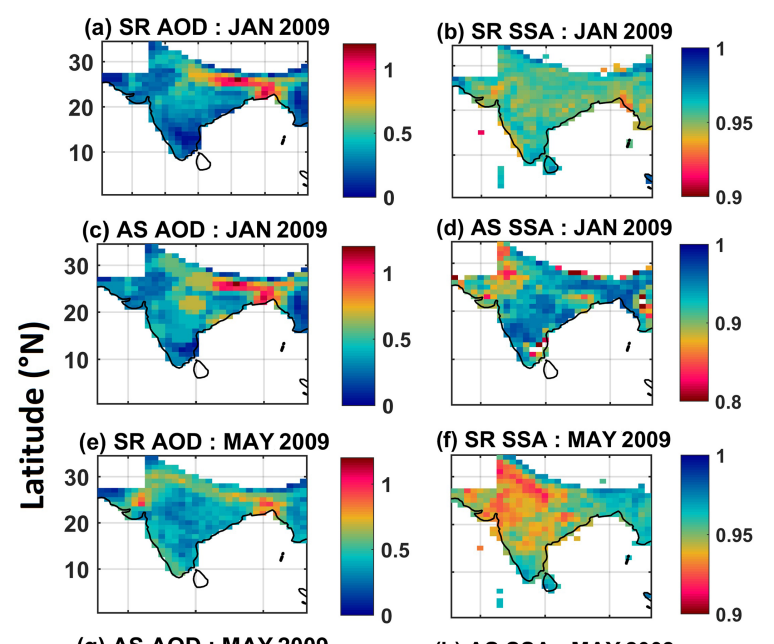

(d) AS SSA : JAN 2009
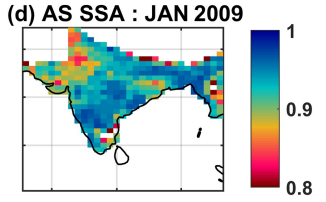

(f) SR SSA : MAY 2009

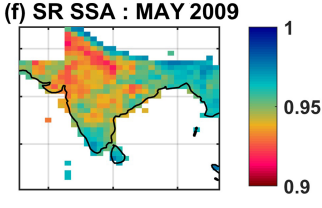

(g) AS AOD : MAY 2009

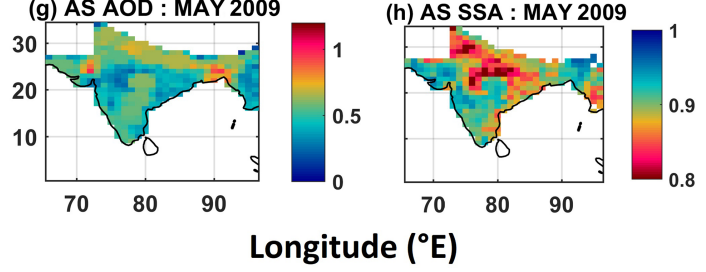

Figure 1. Spatial variation of (a) SR AOD for January 2009, (b) SR SSA for January 2009, (c) AS AOD for January 2009, (d) AS SSA for January 2009, (e) SR AOD for May 2009, (f) SR SSA for May 2009, (g) AS AOD for May 2009 and (h) AS SSA for May 2009.

the most conspicuous being in SSA where the assimilated data show stronger absorption than the satellite-retrieved data over many parts of the domain.

\section{ARF estimation}

For estimating aerosol radiative forcing, we have used the Santa Barbara DISORT Atmospheric Radiative Transfer (SBDART) radiative heat transfer model, which uses the DIScrete Ordinate Radiative Transfer (DISORT) algorithm to solve the radiative heat transfer equation with planeparallel assumption, in the atmosphere with vertical inhomogeneities (Ricchiazzi et al., 1998). The above-described columnar AOD and SSA (Sect. 2) data are used as inputs. Here, the aerosols are considered to be exponentially distributed in vertical direction with the typical scale height of $1.45 \mathrm{~km}$ (Ricchiazzi et al., 1998). The surface reflectance data needed have been taken from MODIS, while vertical distribution of atmospheric gases, except columnar ozone and water vapour, is specified using the tropical environment model provided by SBDART. For columnar ozone and water vapour, datasets for the corresponding period provided, respectively, by OMI and MODIS are used (Ziemke et al., 2006; Gao and Kaufman, 2003). The upward and downward shortwave fluxes at TOA and the surface, (in the wavelength range of 0.2 to $4 \mu \mathrm{m}$ ) are computed using SBDART for each 
hour from 06:00 (approximate local sunrise time in Indian Standard Time; IST) to 18:00 (approximate local sunset time in IST) for each grid point. The net radiative fluxes are then estimated (considering upward negative and downward positive) for "with aerosol" and "without aerosol" conditions and then ARF is estimated as the difference between the net fluxes for the two conditions as has been described in Eqs. (1)-(2).

$$
\begin{aligned}
\mathrm{AS} \mathrm{ARF}_{\mathrm{TOA}}^{*} & =\left(F \downarrow_{\mathrm{TOA}}-F \uparrow \mathrm{TOA}\right)_{\text {with aerosol }} \\
& -\left(F \downarrow_{\mathrm{TOA}}-F \uparrow \mathrm{TOA}\right)_{\text {no aerosol }} \\
\mathrm{AS} \mathrm{ARF}_{\mathrm{srf}}^{*}= & \left(F \downarrow_{\mathrm{srf}}-F \uparrow_{\mathrm{srf}}\right)_{\text {with aerosol }} \\
- & \left(F \downarrow_{\mathrm{srf}}-F \uparrow_{\mathrm{srf}}\right)_{\text {no aerosol }}
\end{aligned}
$$

Here, AS ARF* denotes aerosol radiative forcing estimated using assimilated aerosol properties, while the subscripts TOA and srf denote the top of atmosphere and ground surface, respectively, for a given grid point and solid angle. The upward and downward fluxes over the shortwave spectrum are, respectively, denoted by $F \uparrow$ and $F \downarrow$. The corresponding atmospheric forcing (denoted by AS ARF atm) due to aerosols absorption is then estimated as shown in the following (Eq. 3).

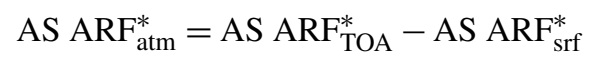

The ARF values estimated in Eqs. (1)-(3), which are specific to a solar-zenith angle (or time of the day) for a given location, are further averaged (over the period of $12 \mathrm{~h}$ ) and then halved in order to estimate the diurnally averaged shortwave ARF for the given grid point. These diurnally averaged ARF at the TOA, surface and in the atmosphere are henceforth referred to as AS ARF TOA, AS ARF $\mathrm{Arf}_{\text {sf }}$ and AS ARF $\mathrm{Atm}_{\mathrm{atm}}$, respectively (without an asterisk).

With a view towards assessing the improvements (or otherwise) of the current estimates over such estimates made using conventional (satellite-retrieved or ground-measured) datasets, we have also estimated direct ARF by using only the satellite-retrieved aerosol products (AOD and SSA) in SBDART for the same period, over the same domain. All other input parameters are kept the same as for AS dataset. The diurnally averaged ARF estimates corresponding to satellite products, at TOA, surface and within the atmosphere are henceforth referred to as SR ARF $\mathrm{AOA}_{\mathrm{T}}, \mathrm{SR} \mathrm{ARF}_{\text {srf }}$ and SR $\mathrm{ARF}_{\mathrm{atm}}$, respectively.

It is to be noted that we have first estimated the upward and downward shortwave radiative fluxes at TOA and surface for each hour from 06:00 (approximate local sunrise time in IST) to 18:00 (approximate local sunset time in IST) by incorporating assimilated and satellite-based aerosol properties into the radiative transfer model for each grid point. The net radiative fluxes are then estimated (considering upward fluxes negative and downward fluxes positive) for "with aerosol" and "without aerosol" conditions, and then radiative forcing $(\mathrm{RF})$ is estimated as the difference between the net fluxes for the two conditions as has been described in Eqs. (1)-(3) from the paper. These ARF values, which are specific to a solarzenith angle (or time of the day) for a given location, are further averaged (over the period of $12 \mathrm{~h}$ ) and then halved in order to estimate the diurnally averaged shortwave ARF for the given grid point.

Further, from each of the forcing estimates made using the two different datasets, we also estimated the difference between the two (referred to as dARF) as

$$
\begin{aligned}
& \mathrm{dARF}_{\mathrm{TOA}}=\mathrm{AS} \mathrm{ARF}_{\mathrm{TOA}}-\mathrm{SR} \mathrm{ARF}_{\mathrm{TOA}} \\
& \mathrm{dARF}_{\mathrm{srf}}=\mathrm{ASARF} \mathrm{ARf}_{\mathrm{srf}}-\mathrm{SR} \mathrm{ARF}_{\mathrm{srf}} \\
& \mathrm{dARF}_{\mathrm{atm}}=\mathrm{ASARF} \mathrm{ARt}_{\mathrm{atm}}-\mathrm{SRARF} \mathrm{Atm}_{\mathrm{atm}} .
\end{aligned}
$$

\section{Results and discussion}

\subsection{Spatial distribution of aerosol radiative forcing}

The regional distributions of the different components of aerosol radiative forcing, estimated as above, are shown in Fig. 2-4 for the representative winter month (January) and in Figs. 5 to 7 for the representative pre-monsoon month (May). Each figure shows the spatial distribution of ARF determined using assimilated datasets (AS ARF), satelliteretrieved datasets (SR ARF) and the difference between the two for TOA, surface and atmosphere. As the dARF calculation has to account for the signs of the respective ARF estimates, positive $\mathrm{dARF}_{\mathrm{TOA}}$ (which is estimated as shown in Eq. 4) indicates smaller magnitudes of AS ARFTOA visà-vis $\mathrm{SR} \mathrm{ARF}_{\mathrm{TOA}}$, and vice versa when both RF estimates are negative, which is the case in general. The same can be said for $\mathrm{dARF}_{\text {srf }}$ (Eq. 5), the difference between two surface forcing estimates which are always negative. However, when

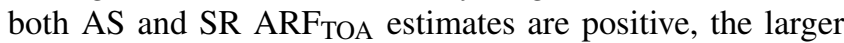
(smaller) magnitudes of $\mathrm{AS} \mathrm{ARF}_{\mathrm{TOA}}$ vis-à-vis $\mathrm{SR} \mathrm{ARF}_{\mathrm{TOA}}$ would yield positive (negative) values of $\mathrm{dARF}_{\mathrm{TOA}}$.

From Figs. 2-4, we can infer the following during winter:

1. Over most of the study domain, ARF estimated using the assimilated datasets shows stronger surface cooling and higher atmospheric warming than that yielded from the satellite-retrieved data, except over outflow region of the Indo-Gangetic Plain. The higher atmospheric forcing when the assimilated dataset is used is mainly contributed by the lower SSA in the assimilated data (due to assimilation with ground-based measurements of aerosol absorption).

2. Over most of the domain, the TOA forcing remains negative in both the estimates, though the magnitude is lower when assimilated data are used. However, weak positive values are seen over the arid regions of the north-west, the Himalayan foothills and a small region on the eastern part of the peninsula (circled in Fig. 2a). 


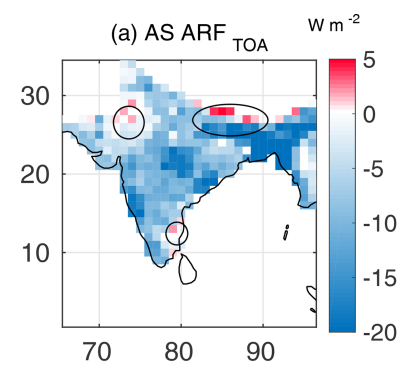

(b) SR ARF ${ }_{\text {TOA }} \quad \mathrm{Wm}^{-2}$
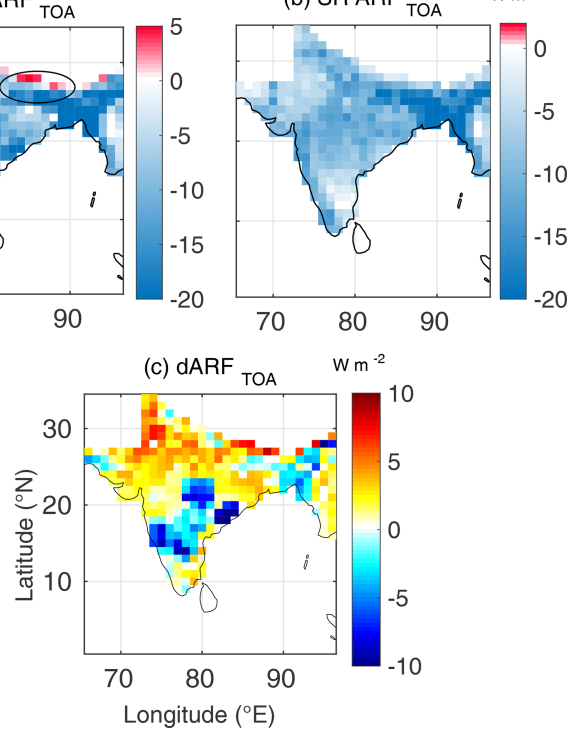

Figure 2. Spatial variation of (a) $A S A R F_{T O A}$ (radiative forcing estimated using AS AOD and AS SSA, at TOA), (b) SR ARF TOA (radiative forcing estimated using SR AOD and SR SSA, at TOA) and (c) $\mathrm{dARF}_{\mathrm{TOA}}$ for January 2009.
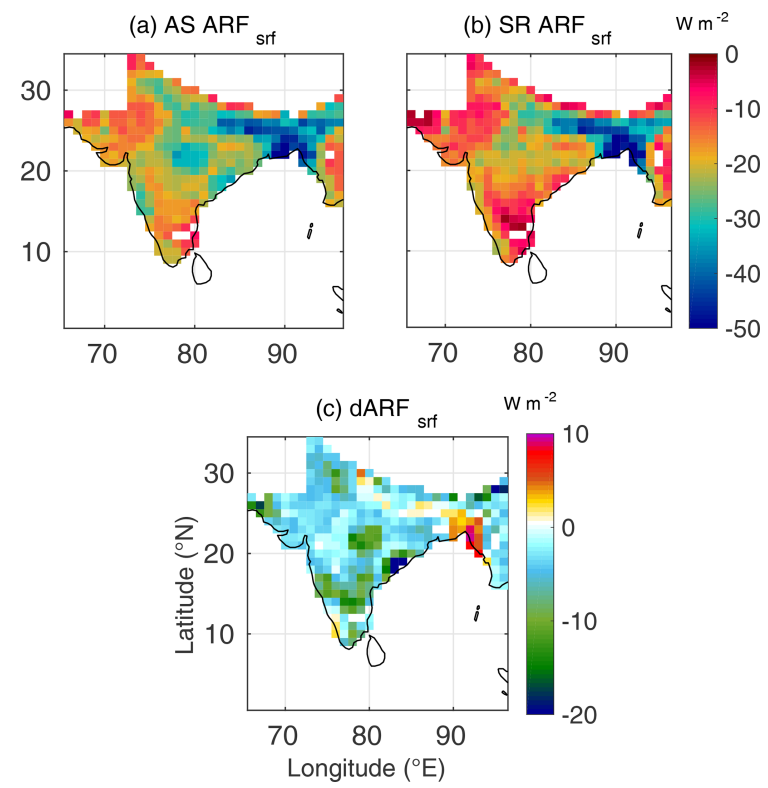

Figure 3. Spatial variation of (a) $\mathrm{AS} \mathrm{ARF}_{\text {srf }}$ (radiative forcing estimated using AS AOD and AS SSA, at the surface), (b) SR ARF (radiative forcing estimated using SR AOD and SR SSA, at the surface) and (c) dARF $F_{\text {srf }}$ for January 2009.

During summer (Figs. 5-7), the seasonal transformation of radiative impacts is clearly seen in the assimilated forcing (mainly due to seasonal change in the aerosol types with anthropogenic aerosols being abundant during winter and natural aerosols during summer). The salient features are as follows:
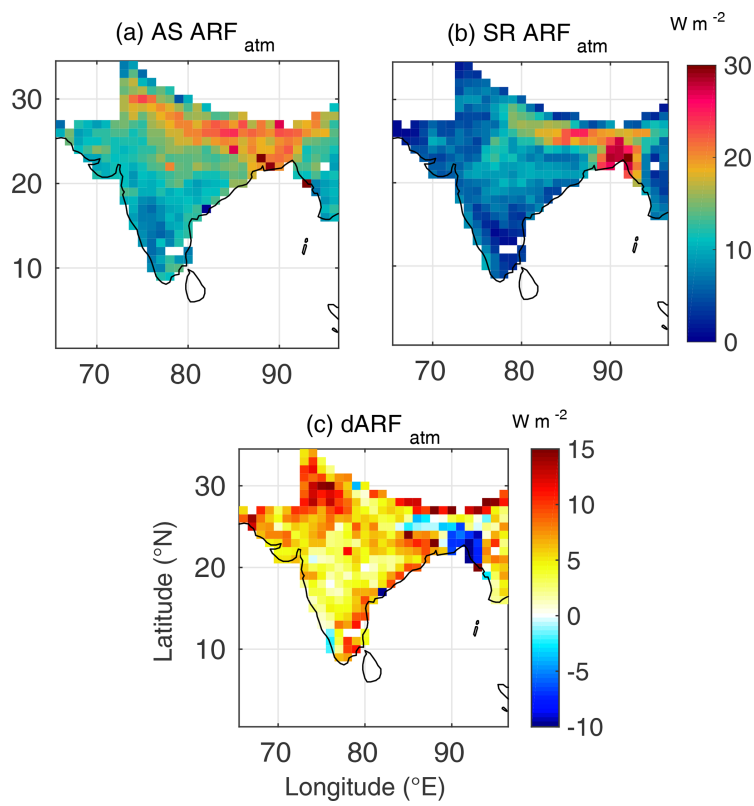

Figure 4. Spatial variation of (a) $A S A F_{a t m}$ (atmospheric forcing estimated using AS AOD and AS SSA), (b) SR ARFatm (atmospheric forcing estimated using SR AOD and SR SSA) and (c) $\mathrm{dARF}_{\text {atm }}$ for January 2009.
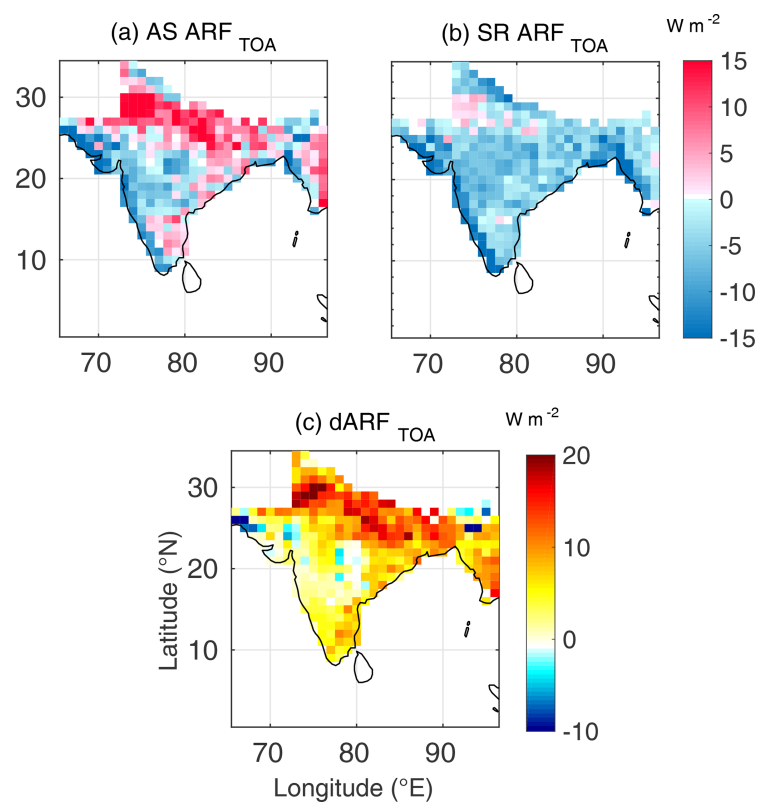

Figure 5. Spatial variation of (a) $A S A R F_{T O A}$ (radiative forcing estimated using AS AOD and AS SSA, at TOA), (b) SR ARF $\mathrm{TOA}_{\mathrm{TOA}}$ (radiative forcing estimated using SR AOD and SR SSA, at TOA) and (c) $\mathrm{dARF}_{\mathrm{TOA}}$ for May 2009.

1. There is a significantly large increase in all the three components of aerosol forcing compared to the wintertime values, primarily due to enhanced aerosol loading in summer. 

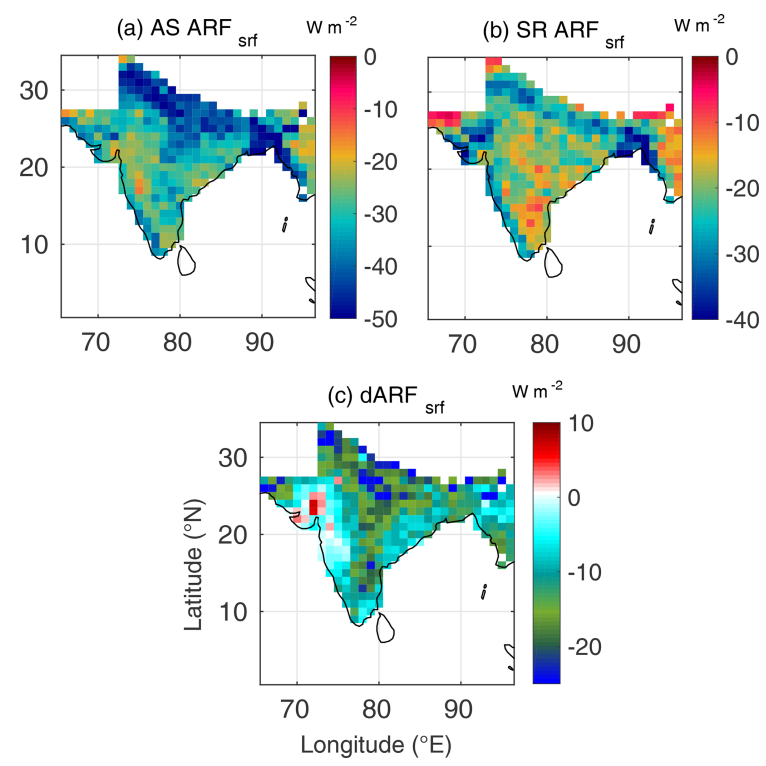

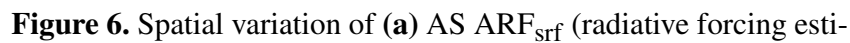
mated using AS AOD and AS SSA, at the surface), (b) SR ARF (radiative forcing estimated using SR AOD and SR SSA, at the surface) and (c) $\mathrm{dARF}_{\text {srf }}$ for May 2009.
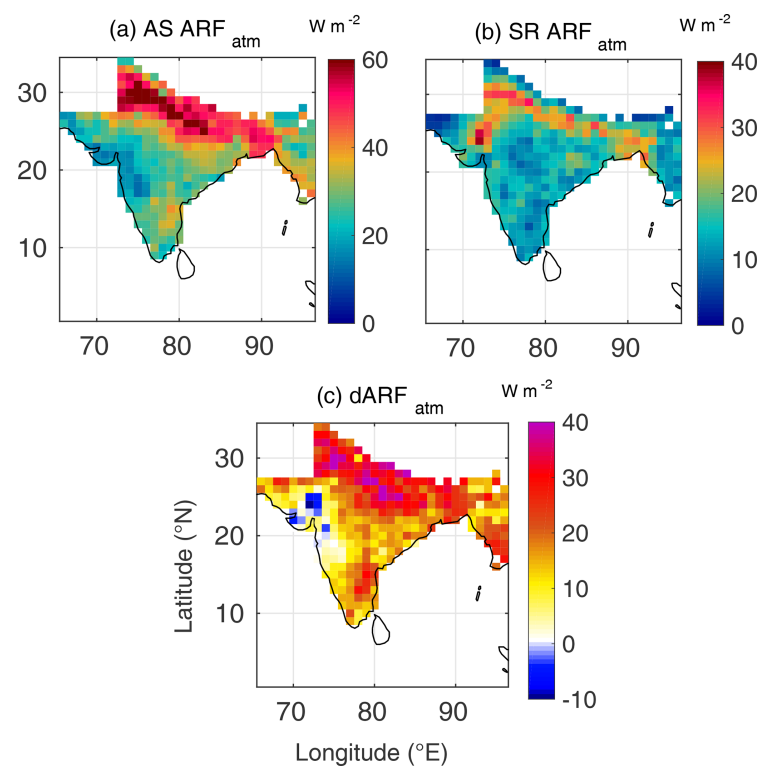

Figure 7. Spatial variation of (a) $A S A R F_{a t m}$ (atmospheric forcing estimated using AS AOD and AS SSA), (b) SR ARF atm (atmospheric forcing estimated using SR AOD and SR SSA) and (c) $\mathrm{dARF}_{\text {atm }}$ for May 2009.

2. This enhancement is seen more conspicuously in the maps using assimilated data (AOD and SSA) as inputs than those generated using satellite-derived data as input over most parts of the region.

3. In sharp contrast to the winter case, during summer, the TOA forcing using assimilated data shows positive values over a large area, with highest values over the Indo-Gangetic Plain (IGP) and eastern Indian landmass, primarily resulting from incorporation of more realistic values of SSA in the assimilated data. Surface forcing remains, nevertheless, negative in both the estimates.

4. Consequently, higher atmospheric forcing results over the entire landmass, except for a small region in the north-west, when assimilated data are used (Fig. 7c).

5. Positive TOA forcing and strong atmospheric absorption over the IGP results from the presence of absorbing aerosol species, (mainly carbonaceous aerosols and mineral dust; Moorthy et al., 2005; Niranjan et al., 2007; Vaishya et al., 2018), which brings down the SSA, and the respective ground-based measurements reflecting the same are assimilated in the AS datasets (Pathak et al., 2019). The strong and vigorous vertical motions within the convective boundary layers (when the surface temperatures are above $40^{\circ} \mathrm{C}$ during large parts of daytime) lift these aerosols to upper levels of the atmosphere (Prijith et al., 2016), thereby further increasing the absorption (Chand et al., 2009). Thus, higher aerosol loading from local as well as remote sources and stronger vertical mixing within deeper planetary boundary layer (especially during pre-monsoon) over the IGP could be responsible for higher ARF over the Indo-Gangetic region vis-à-vis other parts.

However, it is to be noted here that the actual verification of these features regarding vertical distribution of aerosols and their corresponding effects on ARF at regional level demands vertically resolved, gridded aerosol datasets instead of column-integrated aerosol products. Currently, we are in the process of assimilating the entire dataset from airborne measurements over the Indian regions (Babu et al., 2016; Vaishya et al., 2018), carried out during different campaigns since 2016 . The resulting vertically resolved and observationally constrained gridded aerosol properties would be suitable for the regional level assessment of vertical distribution of ARF.

6. The positive TOA forcing values occurring over eastern peninsular India (Figs. 2a and 5a) are primarily due to lower columnar SSA values ( 0.7 to 0.85 ) during winter and pre-monsoonal months as demonstrated in Fig. 1d and $\mathrm{h}$, respectively. These low SSA values indicate the increased presence of black carbon (BC) which can be largely associated with large anthropogenic activities. This region has several major harbours, industries and large urban conglomerates such as Chennai $\left(13.08^{\circ} \mathrm{N}\right.$, $\left.80.27^{\circ} \mathrm{E}\right)$, Vijayawada $\left(16.51^{\circ} \mathrm{N}, 80.65^{\circ} \mathrm{E}\right)$, Visakhapatnam $\left(17.68^{\circ} \mathrm{N}, 83.21^{\circ} \mathrm{E}\right)$, Bengaluru $\left(12.97^{\circ} \mathrm{N}\right.$, $\left.77.59^{\circ} \mathrm{E}\right)$ and Bhubaneswar $\left(20.30^{\circ} \mathrm{N}, 85.42^{\circ} \mathrm{E}\right)$. 


\subsection{Comparison with CERES measurements}

The above-described spatial distribution of aerosol direct forcing and the large season-dependent differences in between the estimates made using assimilated and satelliteretrieved datasets call for a quantitative verification based on independent measurements, which would delineate the datasets that has better accuracy over the study domain. This exercise would also qualify the superior datasets as inputs to climate models for impact assessment. With a view towards accomplishing this, we have compared the TOA fluxes, estimated using the assimilated and satellite-based datasets with spatiotemporally collocated measurements by CERES aboard the Aqua satellite for clear-sky conditions. CERES is a scanning broadband radiometer which measures the upwelling radiances at TOA over three spectral regimes: the shortwave $(0.3-5 \mu \mathrm{m})$, the infrared window $(8-12 \mu \mathrm{m})$ and the total $(0.3-200 \mu \mathrm{m})$. These measured radiances are then converted into the radiative fluxes using the scene-dependent empirical angular distribution models (Loeb et al., 2003), which are then regridded to $1^{\circ} \times 1^{\circ}$ grid. In the present study, we have used the regridded, monthly averaged instantaneous flux measurements at TOA provided by the CERESSSF (single-scan footprint) product for clear-sky conditions. However, it is to be noted that the root mean square (rms) uncertainty $(1 \sigma)$ corresponding to this monthly averaging of instantaneous shortwave flux measurements is around $9 \mathrm{~W} \mathrm{~m}^{-2}$ (over land). In addition, the monthly CERES SW flux measurements also suffer from the uncertainties arising from those in calibration of the CERES instrument $\left(1 \mathrm{~W} \mathrm{~m}^{-2}\right)$ and radiance to flux conversion process $\left(1 \mathrm{~W} \mathrm{~m}^{-2}\right.$; Su et al., 2015).

As the equatorial crossing time (ECT) of Aqua (local solar time for ascending orbit) varies slightly about its mean value of 13:30 LST (local solar time) (Price, 1991; Ignatov et al., 2004), we have estimated the TOA fluxes using the assimilated and satellite-retrieved datasets at time $T$ and $T \pm \sigma_{T}$, where $T$ is the mean equatorial crossing time and $\sigma_{T}$ is the standard deviation in ECTs. The rest of the inputs to SBDART remained the same for the estimates as those given in Sect. 3. The TOA fluxes thus estimated employing assimilated and satellite-based aerosol products are time averaged (over $T$ and $T \pm \sigma_{T}$ ) for each month and then compared with monthly mean CERES-measured fluxes. The aboveestimated time-averaged fluxes corresponding to assimilated and satellite aerosol products are henceforth, respectively, denoted as AS RAD TOA and SR RADTOA, and respective CERES flux measurements are referred to as CERES TOA $_{\text {. }}$ With a view towards quantifying the comparisons, we have computed the deviations of AS RAD ${ }_{\text {TOA }}$ and SR RAD TOA from corresponding CERES measurements for each month during the period of 5 years (2009-2013)(excluding the monsoon months of JJAS, due to extensive cloud cover).
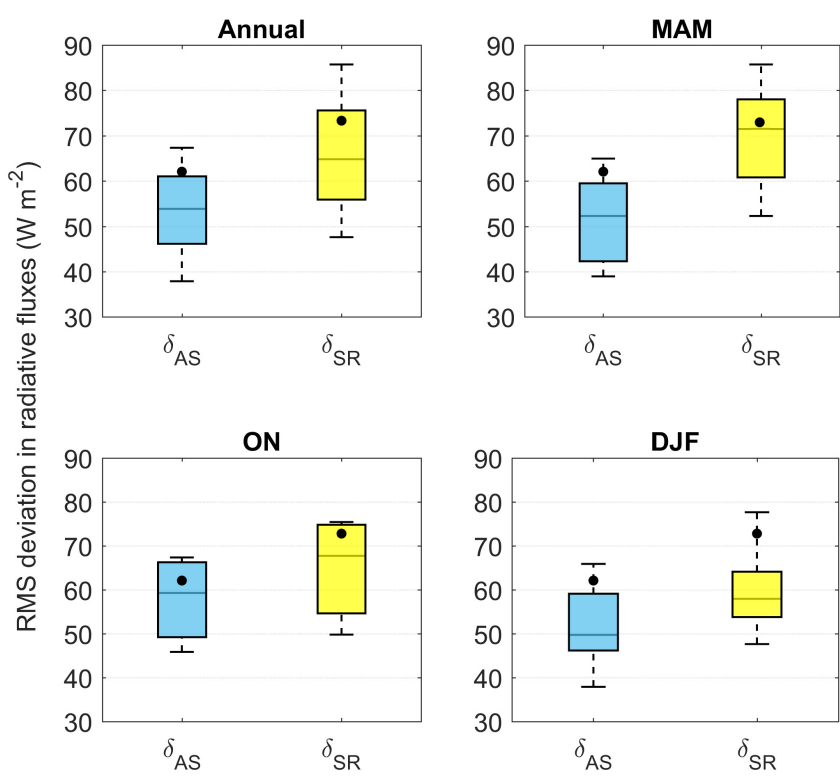

Figure 8. Box-and-whisker plots for monthly $\operatorname{rms}\left(\delta_{\mathrm{AS}}\right)$ (blue coloured box) and $\operatorname{rms}\left(\delta_{\mathrm{SR}}\right)$ (yellow coloured box) for the duration of 2009-2013. The bottom and top ends of the boxes, respectively, denote the 25 th and 75 th percentiles, the median is denoted by the black horizontal line within each box, and the black circle represents the mean of the respective population.

$\delta_{\mathrm{AS}}=\mathrm{AS} \mathrm{RAD}_{\mathrm{TOA}}-\mathrm{CERES}_{\mathrm{TOA}}$
$\delta_{\mathrm{SR}}=\mathrm{SR} \mathrm{RAD}_{\mathrm{TOA}}-\mathrm{CERES}_{\mathrm{TOA}}$

In Eq. (7) (Eq. 8) above, $\delta_{\mathrm{AS}}\left(\delta_{\mathrm{SR}}\right)$ denotes deviations in the absolute magnitudes of TOA fluxes estimated employing assimilated (satellite-retrieved) datasets from the corresponding CERES-measured fluxes. Accordingly, positive values of $\delta_{\mathrm{AS}}\left(\delta_{\mathrm{SR}}\right)$ imply higher magnitudes of the TOA fluxes estimated using the assimilated (satellite) datasets vis-à-vis CERES measurements. The monthly time series of the rms of flux deviations $\left(\delta_{\mathrm{AS}}, \delta_{\mathrm{SR}}\right)$ are presented in Fig. 8 in the form of box-and-whisker plots, for the entire study period (referred to as "annual") as well as for the following three seasons: pre-monsoon (PrM; March-April-May; MAM), winter (December-January-February; DJF) and post-monsoon (PoM; October-November; ON).

Figure 8 unequivocally shows that median and mean of flux deviations are substantially smaller (at $95 \%$ confidence level) for estimates made using the assimilated datasets than when the satellite-retrieved datasets are used for all the seasons as well as for the entire monthly time series represented by the annual case. However, the difference between the two distributions $\left(\delta_{\mathrm{AS}}, \delta_{\mathrm{SR}}\right)$ is more conspicuous during the MAM season (Fig. 8), which is the season of intense aerosol loading over this domain, due to the combined actions of local emissions and long-range transport being thoroughly mixed and vertically lofted by strong thermal con- 
vections. This quantifies the better accuracy of the observationally constrained, assimilated, gridded aerosol products over the satellite-retrieved aerosol products, over the study domain for inputting in ARF estimation.

However, there are significant differences between TOA fluxes estimated using assimilated products and CERES measurements $\left(\sim 40\right.$ to $70 \mathrm{~W} \mathrm{~m}^{-2}$ for the annual case; Fig. 8a). The annual and seasonal mean values of these differences $\left(\mathrm{rms}, \delta_{\mathrm{AS}}\right)$ and the corresponding CERES $\mathrm{TOA}_{\mathrm{T}}$ measurements are provided the Table 1 . It is to be noted that the standard deviation values provided in the Table 1 correspond to annual and seasonal averaging of respective variables over the domain and are representative of the statistical variations.

These differences $\left(\delta_{\mathrm{AS}}\right)$ would arise from the uncertainties

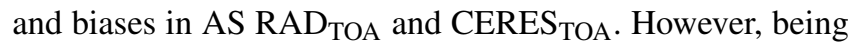
constructed from high-quality direct ground-based measurements (Pathak et al., 2019), the systematic bias in the assimilated aerosol properties and hence in $\mathrm{AS} \mathrm{RAD}_{\mathrm{TOA}}$ tends to be very small. Therefore, the $\delta_{\text {AS }}$ values reported in Fig. 8 and Table 1 would primarily be due to random errors in AS

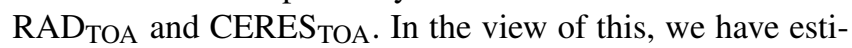
mated the uncertainties in $\mathrm{AS} \mathrm{RAD}_{\mathrm{TOA}}$ which primarily originate from those in assimilated AOD and SSA as well as from averaging of $\mathrm{AS} \mathrm{RAD}_{\mathrm{TOA}}$ over the Aqua satellite crossing duration. The uncertainties in $A S \mathrm{RAD}_{\mathrm{TOA}}$ due to those in assimilated aerosol products are estimated following the procedure similar to that explained in Appendix A for the two representative cases of January and May 2009, and the typical value of rms uncertainty $(1 \sigma)$ in AS RAD $\mathrm{ROA}_{\mathrm{TO}}$ is around $5.8 \mathrm{~W} \mathrm{~m}^{-2}$. Further, the rms uncertainty $(1 \sigma)$ due to temporal averaging of $A S \mathrm{RAD}_{\mathrm{TOA}}$ over the duration corresponding to expected variation in the satellite crossing time is observed to be $7.6 \mathrm{~W} \mathrm{~m}^{-2}$. The uncertainties in instantaneous TOA flux measurements provided by CERES-SSF (monthly averaged) are already described above.

It can be seen from the above discussion and the Table 1 that the estimated rms difference between the AS RAD ${ }_{\text {TOA }}$ and $\mathrm{CERES}_{\mathrm{TOA}}$ (i.e. $\delta_{\mathrm{AS}}$ which varies from $\sim 40$ to $70 \mathrm{~W} \mathrm{~m}$ ${ }^{-2}$ for annual mean case) is substantially contributed by the

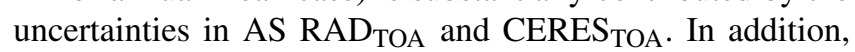
the uncertainties associated with MODIS surface reflectance products and the assumed aerosol phase function would also contribute to those in the AS RAD ${ }_{\mathrm{TOA}}$ and would reflect in $\mathrm{rms}\left(\delta_{\mathrm{AS}}\right)$. It is to be noted here that although the assimilated aerosol products have demonstrated much better confirmation with independent ground-based direct measurements (Pathak et al., 2019) vis-à-vis satellite-based products, over regions where the ground-based measurements are less dense or sparse, they would tend to be very close to or nearly the same as their satellite counterparts which suffer from substantial uncertainties and biases (Zhang and Reid, 2006; Jethva et al., 2014, 2009) as discussed in Pathak et al. (2019) (the Part 1 paper). As such, to further reduce the differences between the model-estimated (using assimilated products) and CERES-measured TOA fluxes, it is required to have denser network of ground-based aerosol measurements. In addition, incorporating spatiotemporally varying aerosol phase function datasets and vertical profiles of aerosol extinction and SSA is expected to reduce the differences between the estimated and measured TOA flux measurements further.

This analysis establishes the improved effectiveness of TOA fluxes estimated using assimilated vis-à-vis satellite products and the similar improvement is implied in the ARF corresponding to assimilated aerosol products than those estimated using their satellite counterparts. In the view of this, we have performed the regional level estimation of the aerosol-induced atmospheric heating rate (columnar) using the atmospheric absorption corresponding to assimilated aerosol datasets and compared it to those estimated using satellite aerosol products.

\subsection{Atmospheric heating rate estimation}

The atmospheric forcing component of ARF is the amount of energy absorbed by the atmosphere, which heats the atmosphere. The heating rate due to aerosol-induced atmospheric absorption is calculated as shown in Eq. (9).

$$
\frac{\partial T}{\partial t}=\frac{g}{C_{p}} \frac{\Delta F}{\Delta P}
$$

Here, $\frac{\partial T}{\partial t}$ is the atmospheric heating rate $\left(\mathrm{K} \mathrm{S}^{-1}\right), g$ is the acceleration due to gravity, $C_{p}$ is the specific heat of air at constant pressure $\left(\sim 1005 \mathrm{~J} \mathrm{~kg}^{-1} \mathrm{~K}^{-1}\right), \Delta F$ is the aerosol-induced atmospheric absorption, and $P$ is the atmospheric pressure. Here, $\Delta P$ is considered to be $300 \mathrm{hPa}$ (pressure varying from 1000 to $700 \mathrm{hPa}$ ) implying that atmospheric aerosols are largely concentrated in the first $3 \mathrm{~km}$ above the ground, which is also supported by observations (Parameswaran et al., 1995; Müller et al., 2001).

The spatial distribution of diurnally averaged atmospheric heating rates estimated using assimilated datasets $\left(\mathrm{HR}_{\mathrm{AS}}\right)$ and its difference from similar estimates made using satelliteretrieved aerosol datasets $\left(\mathrm{HR}_{\mathrm{AS}}-\mathrm{HR}_{\mathrm{SR}}\right)$ are shown in Fig. 9 for two representative months (January and May 2009).

The figure reveals consistently higher heating rates $(\sim 0.6$ to $0.7 \mathrm{~K} \mathrm{~d}^{-1}$ during January 2009 and $\sim 1.5$ to $2.0 \mathrm{~K} \mathrm{~d}^{-1}$ during May) over the IGP than the rest of the subregions. As

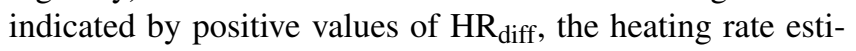
mates using assimilated datasets are consistently higher than those estimated using satellite-derived aerosol products. Further examination of Fig. 9 reveals that there is significant seasonality in the atmospheric heating rate, with pre-monsoonal month (May) exhibiting substantially stronger warming than that during the winter month of January, over most of the Indian region. In view of this, we have examined the seasonal variation in the aerosol radiative forcing over the Indian region in the next section. 
Table 1. Annual and seasonal mean CERES TOA flux measurements and difference between AS RADTOA and CERES $\mathrm{TOA}_{\text {in }} \mathrm{W}^{-2}$.

\begin{tabular}{lrrrr}
\hline & Annual & MAM & ON & DJF \\
\hline CERES TOA flux & $133.12 \pm 54.06$ & $139.29 \pm 59.65$ & $127.16 \pm 42.25$ & $126.87 \pm 47.68$ \\
$\delta_{\text {AS }}$ & $61.01 \pm 29.78$ & $51.51 \pm 8.90$ & $76.01 \pm 43.49$ & $58.46 \pm 28.53$ \\
\hline
\end{tabular}

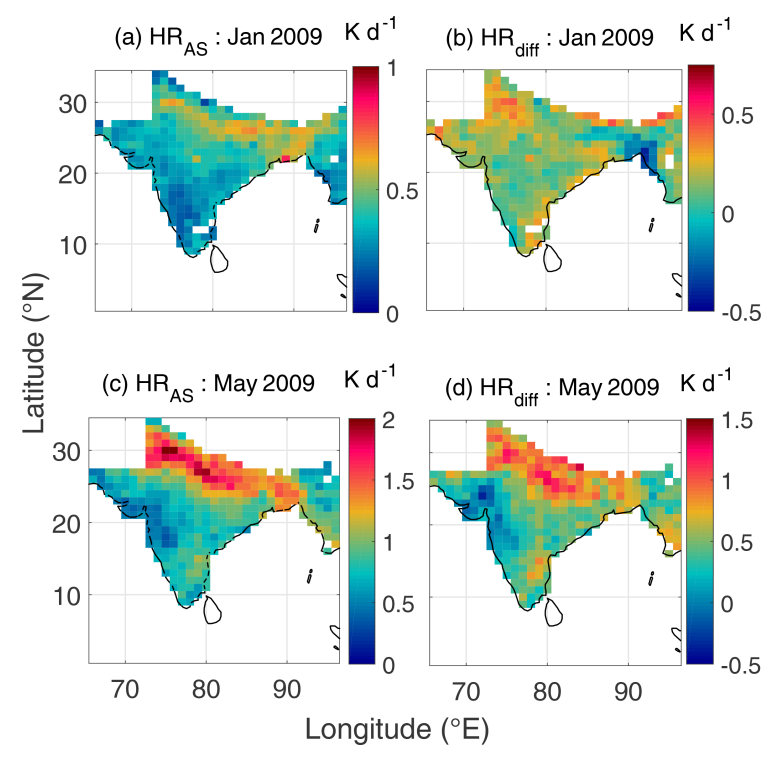

Figure 9. Spatial variation of aerosol-induced atmospheric heating rate (in $\mathrm{K} \mathrm{d}^{-1}$ ) estimated using assimilated aerosol products $\left(\mathrm{HR}_{\mathrm{AS}}\right.$ ) for January and May 2009 (a and c, respectively), difference between aerosol-induced atmospheric heating rate corresponding to assimilated and satellite aerosol products $\left(\mathrm{HR}_{\text {diff }}=\right.$ $\mathrm{HR}_{\mathrm{AS}}-\mathrm{HR}_{\mathrm{SR}}$ ) for January and May 2009 (b and d, respectively).

\subsection{Seasonal and subregional features}

Aerosol types and their properties over the Indian region are known to exhibit significant seasonal variation, both at regional and subregional scales, primarily due to seasonality in the nature of aerosol sources, advection pathways as well as synoptic and mesoscale meteorology (Jethva et al., 2014; Krishna Moorthy et al., 2007; Babu et al., 2013; Vaishya et al., 2018; Pathak et al., 2019). We examine the signatures of these in direct ARF. For this analysis, we have considered four subregions of the spatial domain based on the homogeneity of broad-scale geographical features as detailed in Fig. 10 and Table 2.

The climatological seasonal variation of TOA forcing and atmospheric absorption estimated employing assimilated aerosol products and averaged over four subregions are presented in Figs. 11 and 12, respectively, with panels a-d in each figure, respectively, representing the IGP, NE, PI and WAR. Please note that the vertical lines over the bars in Figs. 11 and 12 indicate the spatiotemporal variation in ARF

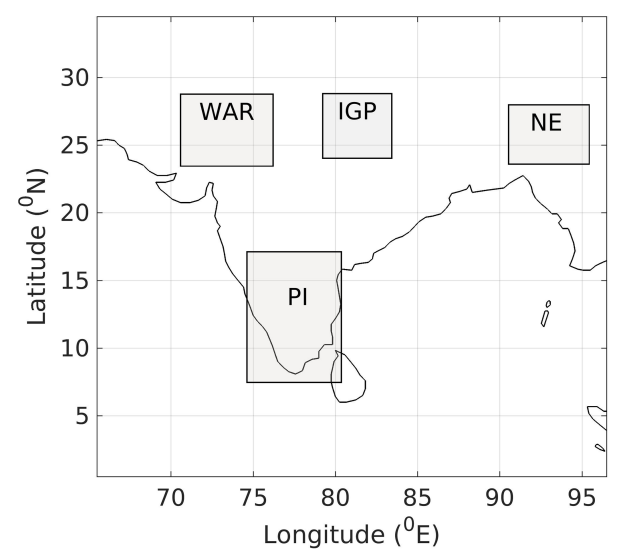

Figure 10. Subregions of the spatial domain. (a) IGP

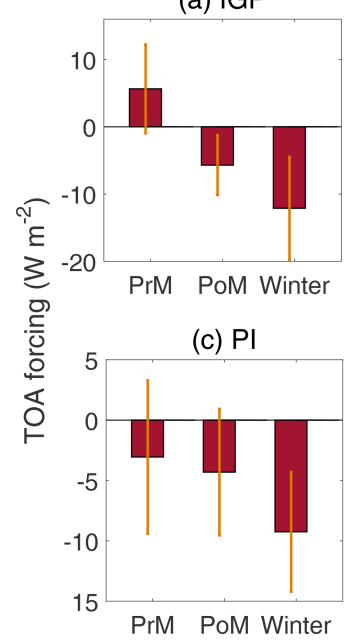

(b) NE

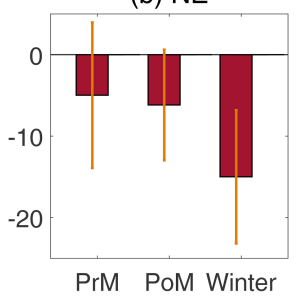

(d) WAR

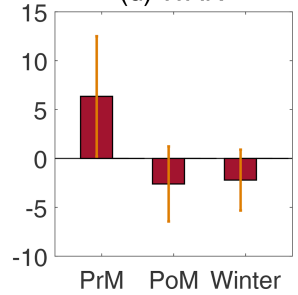

Figure 11. The climatological seasonal variation of aerosol radiative forcing at TOA estimated using assimilated aerosol products and averaged over four subregions: (a) IGP, (b) NE, (c) PI and (d) WAR.

over the respective subregion and not the uncertainties in radiative forcing.

Figure 11 clearly demonstrates the following:

1. The TOA forcing is mostly negative over all the subregions and most of the seasons, except over the two subregions (IGP and WAR), which are highly influenced by advected and locally emitted dust (Banerjee et al., 2019) during pre-monsoon seasons. 
Table 2. Details of subregions considered.

\begin{tabular}{llllrr}
\hline $\begin{array}{l}\text { Sr } \\
\text { no. }\end{array}$ & $\begin{array}{l}\text { Subregion } \\
\text { ID }\end{array}$ & $\begin{array}{l}\text { Subregion } \\
\text { name }\end{array}$ & $\begin{array}{l}\text { Broad } \\
\text { geographical } \\
\text { characteristics }\end{array}$ & $\begin{array}{r}\text { Latitudinal } \\
\text { boundaries } \\
\text { in deg. north }\end{array}$ & $\begin{array}{r}\text { Longitudinal } \\
\text { boundaries } \\
\text { in deg. east }\end{array}$ \\
\hline 1 & IGP & Indo-Gangetic Plain & Plain plateau & $24.5-28.5$ & $78.5-83.5$ \\
2 & NE & North-eastern India & Mountainous & $23.5-27.5$ & $90.5-95.5$ \\
3 & PI & Peninsular India & Coastal and plain & $7.5-17.5$ & $74.5-80.5$ \\
4 & WAR & Western arid region & Arid & $23.5-28.5$ & $70.5-76.5$ \\
\hline
\end{tabular}

(a) IGP

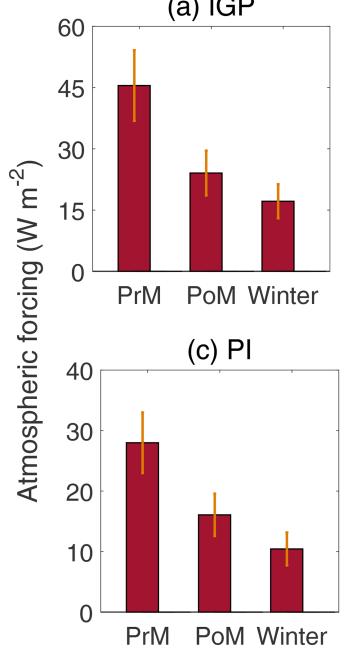

(b) NE

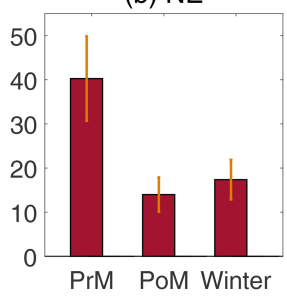

(d) WAR

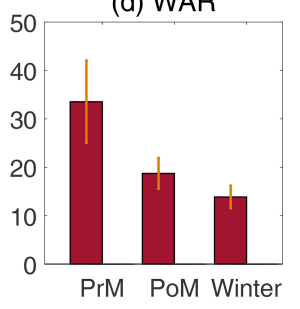

Figure 12. The climatological seasonal variation of atmospheric absorption due to aerosols estimated using assimilated aerosol products and averaged over four subregions: (a) IGP, (b) NE, (c) PI and (d) WAR.

2. Seasonally, the magnitude of TOA forcing is highest during winter and lowest during pre-monsoon over most of the subregions, except WAR (Fig. 11d) for which the highest magnitude of TOA forcing occurs during premonsoon and lowest during winter, again primarily due to the influence of mineral dust.

Almost in agreement with the TOA forcing, atmospheric absorption (Fig. 12) is at maximum during pre-monsoon (when TOA forcing is minimum negative) and least during winter (when TOA forcing is maximum negative) over most of the subregions, except the NE subregion (Fig. 12b), which shows the lowest atmospheric absorption during postmonsoon. The highest values of atmospheric forcing though appear over the IGP (Fig. 12a) and lowest over PI (Fig. 12c).

Further, we have estimated the uncertainties in the ARF estimated using assimilated as well as satellite aerosol products and the exercise revealed that the uncertainties in AS ARF are substantially smaller than those in SR ARF, which is a direct consequence of smaller uncertainties in assimilated AOD and SSA vis-à-vis respective satellite products (Pathak

et al., 2019). The corresponding details are provided in Appendix A.

\section{Summary}

We have estimated shortwave, clear-sky direct aerosol radiative forcing over the Indian region by incorporating gridded, assimilated, multi-year (2009-2013) datasets for monthly AOD and SSA in SBDART and compared its spatiotemporal features with those in ARF estimated using presently available satellite-retrieved aerosol products. This work is the first of its kind over the Indian region that computes regional ARF estimates that employ assimilated, gridded datasets constrained by highly accurate aerosol measurements performed with a dense network of ground-based observatories spanning across the Indian region. In order to examine the accuracy of these ARF estimates, the monthly instantaneous TOA fluxes estimated using assimilated and satelliteretrieved products are compared against the monthly averaged, instantaneous CERES measurements. Finally, we have estimated the aerosol-induced atmospheric warming rates and discussed their spatiotemporal features. The primary findings of the present work are as follows:

1. The TOA fluxes estimated using the assimilated datasets conform better with independent and concurrent spaceborne measurements performed by CERES as compared to those shown by TOA fluxes corresponding to satellite-retrieved datasets. This establishes the higher accuracy of ARF estimated using assimilated vis-à-vis satellite aerosol products.

2. The diurnally averaged ARF corresponding to assimilated aerosol properties depicts significant spatial and temporal diversity not only in terms of the magnitudes but also in the sign of ARF at TOA. The Indo-Gangetic Plain, north-eastern parts and southern parts of peninsular India exhibit either negative forcing with smaller magnitudes or positive forcing, as compared to rest of the region, demonstrating negative TOA forcing of relatively larger magnitudes.

3. The regional distribution of radiative forcing also reveals increased surface cooling and atmospheric absorp- 
tion over the Indo-Gangetic Plain and arid regions from north-western India vis-à-vis rest of the region.

4. Similar large-scale spatial features are also shown by ARF estimated using satellite products; however, they differ from their assimilated counterparts in terms of magnitude as well as sign of TOA forcing.

5. In consonance with the aerosol-induced atmospheric forcing, the atmospheric warming rates exhibit significant spatial heterogeneity $\left(\sim 0.2\right.$ to $\left.2.0 \mathrm{~K} \mathrm{~d}^{-1}\right)$, with the Indo-Gangetic region demonstrating largest values $\left(\sim 0.6\right.$ to $\left.2.0 \mathrm{~K} \mathrm{~d}^{-1}\right)$. In most of the cases, the heating rates corresponding to assimilated products demonstrate substantially increased lower-tropospheric warming vis-à-vis those corresponding to satellite aerosol products.

6. Over most parts of the region, the TOA forcing is negative throughout the year, with maximum magnitudes occurring during winter and minimum during premonsoon, except the Indo-Gangetic Plain and western arid regions over which the sign of TOA forcing flips from positive (during pre-monsoon) to negative (during post-monsoon and winter). However, the atmospheric forcing due to aerosols is highest during pre-monsoon and lowest during winter over almost the entire Indian region.
7. The uncertainties in ARF estimated using assimilated aerosol products are substantially lower than those in ARF estimated using satellite products, which is a natural consequence of smaller uncertainties in assimilated vis-à-vis satellite aerosol products.

On the background of these benefits, the present ARF estimates and the corresponding assimilated aerosol products can be potentially applied for improving the accuracy of aerosol climate impact assessment at regional, subregional and seasonal scales. 


\section{Appendix A: Uncertainties in ARF}

One of the prime challenges in the accurate climate impact assessment of aerosols is posed by the uncertainties in the estimation of direct aerosol radiative effect. These uncertainties primarily emanate from those in the gridded datasets for aerosol properties, mainly AOD and SSA. Past studies have shown that small changes in SSA can even change the sign of aerosol radiative forcing at TOA (Haywood and Shine, 1995, 1997; Heintzenberg et al., 1997; Russell et al., 2000; Takemura et al., 2002; Loeb and Su, 2010; Babu et al., 2016). Against this backdrop, it becomes imperative to assess the uncertainties in the radiative forcing estimates presented in the current study.

For estimation of uncertainties in aerosol radiative forcing, we have derived multiple realizations of diurnally averaged ARF (at TOA, surface and within the atmosphere) at each grid point over the Indian region, with each of these ARF realizations corresponding to a particular AOD and SSA which are perturbed from the original values within their respective uncertainty limits. The uncertainties in assimilated AOD and SSA are estimated as discussed in Part 1 of the two-part paper (Pathak et al., 2019). The uncertainties in SR AOD (which is largely comprised of MODIS AODs) are estimated as $\pm\left(0.03+0.2 \tau_{\mathrm{M}}\right)$ (Sayer et al., 2013) where $\tau_{\mathrm{M}}$ is the corresponding MODIS AOD. The uncertainty in OMI SSA is considered to be \pm 0.05 following Jethva et al. (2014). For a given grid point, the standard deviation across the multiple realizations of ARF is then considered to be the uncertainty in the radiative forcing estimate. Thus, we have estimated the uncertainties in ARF corresponding to assimilated and satellite-based aerosol products.

The rms uncertainties in the ARF at TOA, surface and atmospheric absorption estimated using assimilated aerosol products are presented and compared with those in ARF estimated using satellite-derived aerosol products in Tables A1 and A2, for the two representative months, January and May 2009, respectively.

Tables A1 and A2 demonstrate that uncertainties in AS ARF are substantially smaller than those in SR ARF, which is the consequence of smaller uncertainties in assimilated aerosol products as compared their satellite counterparts. It can further be seen from Tables A1 and A2 that uncertainties in aerosol radiative forcing estimated using assimilated datasets are smallest for the forcing at TOA as compared to surface forcing and atmospheric absorption. This is in contrast with the ARF corresponding to satellite products for which the TOA forcing exhibits the highest uncertainty visà-vis its surface and atmospheric counterparts, which is in line with Chung et al. (2005), in which the global mean TOA forcing (estimated using assimilated product having a quite limited signature of ground-based aerosol data) is demonstrated to have higher uncertainties than those in surface and atmospheric forcing. Further inspection of Tables A1 and A2 reveals that uncertainties in AS ARF during May 2009 are
Table A1. The rms uncertainty in direct aerosol radiative forcing over the Indian region for January 2009.

\begin{tabular}{lrr}
\hline & $\begin{array}{r}\text { Uncertainty } \\
\text { in AS ARF } \\
\text { January 2009 }\end{array}$ & $\begin{array}{r}\text { Uncertainty } \\
\text { in SR ARF } \\
\text { January 2009 }\end{array}$ \\
\hline TOA forcing & 3.24 & 19.62 \\
Surface forcing & 7.29 & 14.85 \\
Atmospheric absorption & 9.81 & 12.67 \\
\hline
\end{tabular}

Table A2. The rms uncertainty in direct aerosol radiative forcing over the Indian region for May 2009.

\begin{tabular}{lrr}
\hline & $\begin{array}{r}\text { Uncertainty } \\
\text { in AS ARF } \\
\text { May 2009 }\end{array}$ & $\begin{array}{r}\text { Uncertainty } \\
\text { in SR ARF } \\
\text { May 2009 }\end{array}$ \\
\hline TOA forcing & 2.64 & 13.10 \\
Surface forcing & 6.61 & 10.55 \\
Atmospheric absorption & 6.24 & 8.49 \\
\hline
\end{tabular}

smaller than those during January 2009. This could be primarily because of the assimilated aerosol datasets for May 2009 assimilating high-quality aerosol measurements from a greater number of stations (19 stations each for AOD and absorption AOD (AAOD) assimilation) vis-à-vis January 2009 (17 and 15 stations for AOD and AAOD assimilation, respectively) leading to reduced uncertainties in assimilated AOD and SSA during May compared to January 2009 and the consequential effect on uncertainties in AS ARF.

Unlike AOD and SSA, there are no extensive groundbased and/or airborne measurements of aerosol size distributions to generate gridded datasets available for estimating the aerosol phase function. As such, we have used phase functions corresponding to appropriate aerosol models from the Optical Properties of Aerosols and Clouds (OPAC; Hess et al., 1998) in order to estimate ARF using SBDART. The estimated rms uncertainties are around $2.2 \%(1 \sigma)$ across the eight streams of Legendre moments used in the radiative transfer model. While AOD and SSA are the biggest contributing factors while estimating ARF, phase function plays a relatively less significant role as ARF is the integrated effect over the hemisphere (not angular).

In order to estimate the sensitivity of ARF estimates to the expected variations in the above aerosol phase function, we have simulated the ARF (at TOA, the surface and within the atmosphere) for the representative month of January 2009, over the entire Indian region. Each of these simulations was carried out by incorporating Legendre moments of aerosol phase function corresponding to each of the continental aerosol models provided in OPAC along with columnar, assimilated AOD and SSA in SBDART. The uncertainty of ARF with regard to that phase function is then estimated as 1 standard deviation across the multiple ARF simulations. 
This analysis has revealed that the rms uncertainty $(1 \sigma)$ in ARF at TOA, surface and in the atmosphere is around $4 \%$, $0.22 \%$ and $0.05 \%$, respectively. This analysis shows that the present ARF estimates corresponding to assimilated aerosol products are substantially robust with regard to expected variations in aerosol phase function; however, further improvement in accuracies of the ARF estimation will be possible when realistic size distribution data are generated in the future. 
Data availability. The assimilated AOD and AAOD products can be downloaded from http://dccc.iisc.ac.in/aerosoldata/ (last access: 13 September 2019; Pathak et al., 2019). The MODIS Terra and Aqua aerosol optical depth monthly, L3, global, 1 CMG datasets were acquired from the Level-1 and Atmosphere Archive and Distribution System (LAADS) Distributed Active Archive Center (DAAC), located in the Goddard Space Flight Center in Greenbelt, Maryland (https://ladsweb.nascom.nasa.gov/, last access: 13 September 2019; Levy et al., 2013; Hsu et al., 2013; Sayer et al., 2013).

Author contributions. HSP carried out estimation of aerosol radiative forcing and further analysis of the data under the guidance of SKS, KKM and RSN. HSP was also primarily responsible for writing the manuscript, which was further reviewed and edited by KKM, SKS and RSN. The valuable inputs regarding aerosols radiative forcing estimation were provided by SKS and KKM.

Competing interests. The authors declare that they have no conflict of interest.

Special issue statement. This article is part of the special issue "Interactions between aerosols and the South West Asian monsoon". It is not associated with a conference.

Acknowledgements. This work is carried out as a part of the project titled "South West Asian Aerosol Monsoon Interactions (SWAAMI)" funded by the Ministry of Earth Sciences (MoES), New Delhi. We thank Suredran Nair Suresh Babu, Mohanan R. Manoj and all the ARFINET investigators for the continuous efforts and support provided in maintaining the network as well as in collecting and processing the data. Sreedharan Krishnakumari Satheesh would like to thank SERB-DST for the J. C. Bose Fellowship. MISR aerosol optical depth, monthly L3 global data were obtained from the NASA Langley Research Center Atmospheric Science Data Center. We also acknowledge Global Modeling and Assimilation Office (GMAO) and the GES DISC for distribution of MERRA data. We are thankful to Sivaramakrishnan Lakshmivarahan for his valuable guidance regarding data assimilation techniques. We also thank Hiren Jethva from NASA, GSFC for providing the OMI data.

Financial support. This research has been supported by the Ministry of Earth Sciences (grant no. MM/NERC-MoES-1/2014/002).

Review statement. This paper was edited by B. V. Krishna Murthy and reviewed by two anonymous referees.

\section{References}

Babu, S. S. and Moorthy, K. K.: Aerosol black carbon over a tropical coastal station in India, Geophys. Res. Lett., 29, 13-1-13-4, https://doi.org/10.1029/2002GL015662, 2002.

Babu, S. S., Manoj, M. R., Moorthy, K. K., Gogoi, M. M., Nair, V. S., Kompalli, S. K., Satheesh, S. K., Niranjan, K., Ramagopal, K., Bhuyan, P. K., and Singh, D.: Trends in aerosol optical depth over Indian region: Potential causes and impact indicators, J. Geophys. Res.-Atmos., 118, 11794-11806, https://doi.org/10.1002/2013JD020507, 2013.

Babu, S. S., Nair, V. S., Gogoi, M. M., and Moorthy, K. K.: Seasonal variation of vertical distribution of aerosol single scattering albedo over Indian sub-continent: RAWEX aircraft observations, Atmos. Environ., 125, 312-323, https://doi.org/10.1016/j.atmosenv.2015.09.041, 2016.

Banerjee, P., Satheesh, S. K., Moorthy, K. K., Nanjundiah, R. S., and Nair, V. S.: Long-Range Transport of Mineral Dust to the Northeast Indian Ocean: Regional versus Remote Sources and the Implications, J. Climate, 32, 1525-1549, https://doi.org/10.1175/JCLI-D-18-0403.1, 2019.

Boucher, O. and Anderson, T. L.: General circulation model assessment of the sensitivity of direct climate forcing by anthropogenic sulfate aerosols to aerosol size and chemistry, J. Geophys. Res.Atmos., 100, 26117-26134, https://doi.org/10.1029/95JD02531, 1995.

Boucher, O., Randall, D., Artaxo, P., Bretherton, C., Feingold, G., Forster, P., Kerminen, V.-M., Kondo, Y., Liao, H., Lohmann, U., Rasch, P., Satheesh, S., Sherwood, S., Stevens, B., and Zhang, X.: Clouds and Aerosols, Cambridge University Press, Cambridge, United Kingdom and New York, NY, USA, https://doi.org/10.1017/CBO9781107415324.016, 2013.

Chand, D., Wood, R., L. Anderson, T., K. Satheesh, S., and Charlson, R.: Satellite-derived direct radiative effect of aerosols dependent on cloud cover, Nat. Geosci., 2, 181-184, https://doi.org/10.1038/ngeo437, 2009.

Chung, C. E., Ramanathan, V., Kim, D., and Podgorny, I. A.: Global anthropogenic aerosol direct forcing derived from satellite and ground-based observations, J. Geophys. Res.-Atmos., 110, D24, https://doi.org/10.1029/2005jd006356, 2005.

Chung, C. E., Ramanathan, V., Carmichael, G., Kulkarni, S., Tang, Y., Adhikary, B., Leung, L. R., and Qian, Y.: Anthropogenic aerosol radiative forcing in Asia derived from regional models with atmospheric and aerosol data assimilation, Atmos. Chem. Phys., 10, 6007-6024, https://doi.org/10.5194/acp-106007-2010, 2010.

Diner, D. J., Beckert, J. C., Reilly, T. H., Bruegge, C. J., Conel, J. E., Kahn, R. A., Martonchik, J. V., Ackerman, T. P., Davies, R., Gerstl, S. A. W., Gordon, H. R., Muller, J. P., Myneni, R. B., Sellers, P. J., Pinty, B., and Verstraete, M. M.: Multi-angle Imaging SpectroRadiometer (MISR) instrument description and experiment overview, IEEE T. Geosci. Remote, 36, 1072-1087, https://doi.org/10.1109/36.700992, 1998.

Gao, B.-C. and Kaufman, Y. J.: Water vapor retrievals using Moderate Resolution Imaging Spectroradiometer (MODIS) near-infrared channels, J. Geophys. Res.-Atmos., 108, D13, https://doi.org/10.1029/2002JD003023, 2003.

Haywood, J. M. and Shine, K. P.: The effect of anthropogenic sulfate and soot aerosol on the clear sky plan- 
etary radiation budget, Geophys. Res. Lett., 22, 603-606, https://doi.org/10.1029/95GL00075, 1995.

Haywood, J. M. and Shine, K. P.: Multi-spectral calculations of the direct radiative forcing of tropospheric sulphate and soot aerosols using a column model, Q. J. Roy. Meteor. Soc., 123, 1907-1930, https://doi.org/10.1002/qj.49712354307, 1997.

Heintzenberg, J., Charlson, R., Clarke, A., Liousse, C., Ramaswamy, V., Shine, K., Wendisch, M., and Helas, G.: Measurements and modelling of aerosol single-scattering albedo: Progress, problems and prospects, Contributions to Atmospheric Physics, 70, 249-263, 1997.

Hess, M., Koepke, P., and Schult, I.: Optical properties of aerosols and clouds: The software package OPAC, B. Am. Meteorol. Soc., 79, 831-844, 1998.

Hsu, N., Jeong, M.-J., Bettenhausen, C., Sayer, A., Hansell, R., Seftor, C., Huang, J., and Tsay, S.-C.: Enhanced Deep Blue aerosol retrieval algorithm: The second generation, J. Geophys. Res.-Atmos., 118, 9296-9315, 2013.

Ignatov, A., Laszlo, I., Harrod, E. D., Kidwell, K. B., and Goodrum, G. P.: Equator crossing times for NOAA, ERS and EOS sunsynchronous satellites, Int. J. Remote Sens., 25, 5255-5266, https://doi.org/10.1080/01431160410001712981, 2004.

Jacobson, M. Z.: Global direct radiative forcing due to multicomponent anthropogenic and natural aerosols, J. Geophys. Res.Atmos., 106, 1551-1568, 2001.

Jethva, H., Satheesh, S. K., and Srinivasan, J.: Seasonal variability of aerosols over the Indo-Gangetic basin, J. Geophys. Res.Atmos., 110, D21204, https://doi.org/10.1029/2005JD005938, 2005.

Jethva, H., Satheesh, S., Srinivasan, J., and Moorthy, K. K.: How good is the assumption about visible surface reflectance in MODIS aerosol retrieval over land? A comparison with aircraft measurements over an urban site in India, IEEE T. Geosci. Remote, 47, 1990-1998, 2009.

Jethva, H., Torres, O., and Ahn, C.: Global assessment of OMI aerosol single-scattering albedo using ground-based AERONET inversion, J. Geophys. Res.-Atmos., 119, 90209040, https://doi.org/10.1002/2014JD021672, 2014.

Kim, S.-W., Berthier, S., Raut, J.-C., Chazette, P., Dulac, F., and Yoon, S.-C.: Validation of aerosol and cloud layer structures from the space-borne lidar CALIOP using a ground-based lidar in Seoul, Korea, Atmos. Chem. Phys., 8, 3705-3720, https://doi.org/10.5194/acp-8-3705-2008, 2008.

Kompalli, S. K., Babu, S. S., Moorthy, K. K., Manoj, M., Kumar, N. K., Shaeb, K. H. B., and Joshi, A. K.: Aerosol black carbon characteristics over Central India: Temporal variation and its dependence on mixed layer height, Atmos. Res., 147, 27-37, 2014.

Krishna Moorthy, K., Suresh Babu, S., and Satheesh, S. K.: Temporal heterogeneity in aerosol characteristics and the resulting radiative impact at a tropical coastal station - Part 1: Microphysical and optical properties, Ann. Geophys., 25, 2293-2308, https://doi.org/10.5194/angeo-25-2293-2007, 2007.

Levelt, P. F., Hilsenrath, E., Leppelmeier, G. W., van den Oord, G. H. J., Bhartia, P. K., Tamminen, J., de Haan, J. F., and Veefkind, J. P.: Science objectives of the ozone monitoring instrument, IEEE T. Geosci. Remote, 44, 1199-1208, https://doi.org/10.1109/TGRS.2006.872336, 2006.

Levy, R. C., Mattoo, S., Munchak, L. A., Remer, L. A., Sayer, A. M., Patadia, F., and Hsu, N. C.: The Collection 6 MODIS aerosol products over land and ocean, Atmos. Meas. Tech., 6, 29893034, https://doi.org/10.5194/amt-6-2989-2013, 2013.

Loeb, N. G. and Su, W.: Direct Aerosol Radiative Forcing Uncertainty Based on a Radiative Perturbation Analysis, J. Climate, 23, 5288-5293, https://doi.org/10.1175/2010JCLI3543.1, 2010.

Loeb, N. G., Manalo-Smith, N., Kato, S., Miller, W. F., Gupta, S. K., Minnis, P., and Wielicki, B. A.: Angular Distribution Models for Top-of-Atmosphere Radiative Flux Estimation from the Clouds and the Earth's Radiant Energy System Instrument on the Tropical Rainfall Measuring Mission Satellite. Part I: Methodology, J. Appl. Meteorol., 42, 240-265, https://doi.org/10.1175/15200450(2003)042<0240:ADMFTO>2.0.CO;2, 2003.

Moorthy, K. K., Sunilkumar, S. V., Pillai, P. S., Parameswaran, K., Nair, P. R., Ahmed, Y. N., Ramgopal, K., Narasimhulu, K., Reddy, R. R., Vinoj, V., Satheesh, S. K., Niranjan, K., Rao, B. M., Brahmanandam, P. S., Saha, A., Badarinath, K. V. S., Kiranchand, T. R., and Latha, K. M.: Wintertime spatial characteristics of boundary layer aerosols over peninsular India, J. Geophys. Res.-Atmos., 110, D08207, https://doi.org/10.1029/2004JD005520, 2005.

Müller, D., Franke, K., Wagner, F., Althausen, D., Ansmann, A., Heintzenberg, J., and Verver, G.: Vertical profiling of optical and physical particle properties over the tropical Indian Ocean with six-wavelength lidar: 2. Case studies, J. Geophys. Res.-Atmos., 106, 28577-28595, https://doi.org/10.1029/2000JD900785, 2001.

Myhre, G., Bellouin, N., Berglen, T. F., Berntsen, T. K., Boucher, O., Grini, A., Isaksen, I. S. A., Johnsrud, M., Mishchenko, M. I., Stordal, F., and Tanré, D.: Comparison of the radiative properties and direct radiative effect of aerosols from a global aerosol model and remote sensing data over ocean, Tellus B, 59, 115-129, 2007.

Myhre, G., Berglen, T. F., Johnsrud, M., Hoyle, C. R., Berntsen, T. K., Christopher, S. A., Fahey, D. W., Isaksen, I. S. A., Jones, T. A., Kahn, R. A., Loeb, N., Quinn, P., Remer, L., Schwarz, J. P., and Yttri, K. E.: Modelled radiative forcing of the direct aerosol effect with multi-observation evaluation, Atmos. Chem. Phys., 9, 1365-1392, https://doi.org/10.5194/acp-9-1365-2009, 2009.

Niranjan, K., Sreekanth, V., Madhavan, B. L., and Krishna Moorthy, K.: Aerosol physical properties and Radiative forcing at the outflow region from the Indo-Gangetic plains during typical clear and hazy periods of wintertime, Geophys. Res. Lett., 34, 19, https://doi.org/10.1029/2007GL031224, 2007.

Parameswaran, K., Vijayakumar, G., Krishna Murthy, B. V., and Krishna Moorthy, K.: Effect of Wind Speed on Mixing Region Aerosol Concentrations at a Tropical Coastal Station, J. Appl. Meteorol., 34, 1392-1397, https://doi.org/10.1175/15200450(1995)034<1392:EOWSOM>2.0.CO;2, 1995.

Pathak, B., Kalita, G., Bhuyan, K., Bhuyan, P. K., and Moorthy, K. K.: Aerosol temporal characteristics and its impact on shortwave radiative forcing at a location in the northeast of India, J. Geophys. Res.-Atmos., 115, D19, https://doi.org/10.1029/2009JD013462, 2010.

Pathak, H. S., Satheesh, S. K., Nanjundiah, R. S., Moorthy, K. K., Lakshmivarahan, S., and Babu, S. N. S.: Assessment of regional aerosol radiative effects under the SWAAMI campaign Part 1: Quality-enhanced estimation of columnar aerosol extinction and absorption over the Indian subcontinent, Atmos. Chem. Phys., 19, 11865-11886, https://doi.org/10.5194/acp-19-118652019, 2019. 
Penner, J. E., Charlson, R. J., Hales, J. M., Laulainen, N. S., Leifer, R., Novakov, T., Ogren, J., Radke, L. F., Schwartz, S. E., and Travis, L.: Quantifying and Minimizing Uncertainty of Climate Forcing by Anthropogenic Aerosols, B. Am. Meteorol. Soc., 75, 375-400, https://doi.org/10.1175/15200477(1994)075<0375:QAMUOC>2.0.CO;2, 1994.

Price, J. C.: Timing of NOAA afternoon passes, Int. J. Remote Sens., 12, 193-198, https://doi.org/10.1080/01431169108929644, 1991.

Prijith, S., Suresh Babu, S., Lakshmi, N., Satheesh, S., and Krishna Moorthy, K.: Meridional gradients in aerosol vertical distribution over Indian Mainland: Observations and model simulations, Atmos. Environ., 125, 337-345, https://doi.org/10.1016/j.atmosenv.2015.10.066, 2016.

Ramanathan, V. and Carmichael, G.: Global and regional climate changes due to black carbon, Nat. Geosci., 1, 221-227, 2008.

Ricchiazzi, P., Yang, S., Gautier, C., and Sowle, D.: SBDART: A Research and Teaching Software Tool for PlaneParallel Radiative Transfer in the Earth's Atmosphere, B. Am. Meteorol. Soc., 79, 2101-2114, https://doi.org/10.1175/15200477(1998)079<2101:SARATS>2.0.CO;2, 1998.

Russell, P., Redemann, J., Schmid, B., Bergstrom, R., Livingston, J., McIntosh, D., Hartley, S., Hobbs, P., Quinn, P., Carrico, C., and Hipskind, R.: Comparison of Aerosol Single Scattering Albedos Derived By Diverse Techniques in Two North Atlantic Experiments, J. Atmos. Sci., 59, 609-619, https://doi.org/10.1175/15200469(2002)059<0609:COASSA>2.0.CO;2, 2000.

Satheesh, S., Srinivasan, J., and Moorthy, K.: Spatial and temporal heterogeneity in aerosol properties and radiative forcing over Bay of Bengal: Sources and role of aerosol transport, J. Geophys. Res.-Atmos., 111, D8, https://doi.org/10.1029/2005JD006374, 2006.

Sayer, A. M., Hsu, N. C., Bettenhausen, C., and Jeong, M.-J.: Validation and uncertainty estimates for MODIS Collection 6 "Deep Blue" aerosol data, J. Geophys. Res.-Atmos., 118, 7864-7872, https://doi.org/10.1002/jgrd.50600, 2013.

Schulz, M., Textor, C., Kinne, S., Balkanski, Y., Bauer, S., Berntsen, T., Berglen, T., Boucher, O., Dentener, F., Guibert, S., Isaksen, I. S. A., Iversen, T., Koch, D., Kirkevåg, A., Liu, X., Montanaro, V., Myhre, G., Penner, J. E., Pitari, G., Reddy, S., Seland, Ø., Stier, P., and Takemura, T.: Radiative forcing by aerosols as derived from the AeroCom present-day and pre-industrial simulations, Atmos. Chem. Phys., 6, 5225-5246, https://doi.org/10.5194/acp6-5225-2006, 2006.

Schwartz, S. E.: Uncertainty Requirements in Radiative Forcing of Climate Change, J. Air Waste Manage., 54, 1351-1359, https://doi.org/10.1080/10473289.2004.10471006, 2004.
Sinha, P. R., Dumka, U. C., Manchanda, R. K., Kaskaoutis, D. G., Sreenivasan, S., Krishna Moorthy, K., and Suresh Babu, S.: Contrasting aerosol characteristics and radiative forcing over Hyderabad, India due to seasonal mesoscale and synopticscale processes, Q. J. Roy. Meteor. Soc., 139, 434-450, https://doi.org/10.1002/qj.1963, 2013.

$\mathrm{Su}$, W., Corbett, J., Eitzen, Z., and Liang, L.: Next-generation angular distribution models for top-of-atmosphere radiative flux calculation from CERES instruments: validation, Atmos. Meas. Tech., 8, 3297-3313, https://doi.org/10.5194/amt-8-3297-2015, 2015.

Suresh Babu, S., Krishna Moorthy, K., and Satheesh, S. K.: Temporal heterogeneity in aerosol characteristics and the resulting radiative impacts at a tropical coastal station - Part 2: Direct short wave radiative forcing, Ann. Geophys., 25, 2309-2320, https://doi.org/10.5194/angeo-25-2309-2007, 2007.

Takemura, T., Nakajima, T., Dubovik, O., Holben, B. N., and Kinne, S.: Single-Scattering Albedo and Radiative Forcing of Various Aerosol Species with a Global Three-Dimensional Model, J. Climate, 15, 333-352, https://doi.org/10.1175/15200442(2002)015<0333:SSAARF>2.0.CO;2, 2002.

Torres, O., Tanskanen, A., Veihelmann, B., Ahn, C., Braak, R., Bhartia, P. K., Veefkind, P., and Levelt, P.: Aerosols and surface UV products from Ozone Monitoring Instrument observations: An overview, J. Geophys. Res.-Atmos., 112, D24S47, https://doi.org/10.1029/2007JD008809, 2007.

Vaishya, A., Babu, S. N. S., Jayachandran, V., Gogoi, M. M., Lakshmi, N. B., Moorthy, K. K., and Satheesh, S. K.: Large contrast in the vertical distribution of aerosol optical properties and radiative effects across the Indo-Gangetic Plain during the SWAAMI-RAWEX campaign, Atmos. Chem. Phys., 18, 1766917685, https://doi.org/10.5194/acp-18-17669-2018, 2018.

Zhang, J. and Reid, J. S.: MODIS aerosol product analysis for data assimilation: Assessment of over-ocean level 2 aerosol optical thickness retrievals, J. Geophys. Res.-Atmos., 111, D22207, https://doi.org/10.1029/2005JD006898, 2006.

Ziemke, J. R., Chandra, S., Duncan, B. N., Froidevaux, L., Bhartia, P. K., Levelt, P. F., and Waters, J. W.: Tropospheric ozone determined from Aura OMI and MLS: Evaluation of measurements and comparison with the Global Modeling Initiative's Chemical Transport Model, J. Geophys. Res.-Atmos., 111, D19, https://doi.org/10.1029/2006JD007089, 2006. 